\title{
ESTRATEGIAS EDITORIALES EN EL TEATRO DEL ÚLTIMO LOPE DE VEGA
}

\author{
JESús GómEz (Universidad Autónoma de Madrid)
}

Cita Recomendada: Jesús Gómez, «Estrategias editoriales en el teatro del último Lope de Vega», Anuario Lope de Vega. Texto, literatura, cultura, XXVIII (2022), pp. 176-204.

DOI: <https://doi.org/10.5565/rev/anuariolopedevega.436>

Fecha de recepción: 22 de junio de 2021 / Fecha de aceptación: 7 de julio de 2021

\section{RESUMEN}

Este artículo se centra en la producción teatral del último Lope de Vega, entre 1621 y 1635, para valorar las diferentes estrategias editoriales adoptadas en la publicación de sus obras dramáticas, desde las dos Partes XXI-XXII publicadas el mismo año de su muerte a la edición de La vega del Parnaso. Dentro del periodo acotado, se presta especial atención al Diálogo militar como ejemplo del mecenazgo que se percibe en el teatro de Lope de Vega.

Palabras ClaVE: Lope último; teatro; mecenazgo; Diálogo militar.

ABSTRACT: Editorial Strategies in the Theatre of the Last Lope de Vega.

This article focuses on the last theatrical production period of Lope de Vega, between 1621 and 1635, to evaluate the different editorial strategies used for the publication of his dramatic plays from the two Partes de comedias XXI-XXII published the year of his death to the edition of La vega del Parnaso. Within the limited period, special attention is paid to the Diálogo militar as an example of the patronage that is perceived in Lope de Vega's theatre.

KEYwords: Last Lope; Theatre; Patronage; Diálogo militar. 
$\mathrm{E}$ n la trayectoria literaria de un escritor cuando se acerca al final de su vida, se produce una divergencia entre el legado póstumo de su obra literaria, al quedar originales inéditos o proyectos inacabados, y el momento siempre puntual de su desaparición física. Una divergencia que puede ser mayor o menor, en proporción directa con su plenitud creadora o con su muerte más o menos imprevista. A pesar de las adversas circunstancias vitales que afectaron al último Lope de Vega, según sus biógrafos más rigurosos, el escritor madrileño prolongó la madurez creativa hasta el mismo año de su fallecimiento en $1635 .{ }^{1}$ El lunes 27 de agosto expiró, un día después de haber mandado redactar su segundo testamento. ${ }^{2}$

La magnitud de la obra lopesca no solo en su teatro, sino también en su poesía y en las diversas variedades de la prosa de ficción, hizo inevitable por la proverbial fecundidad o facilidad del Fénix de los Ingenios que dejase proyectos que solo pudieron editarse de manera póstuma, como La vega del Parnaso, o que fueron continuados póstumamente, como la inacabada serie editorial de las sucesivas Partes de sus comedias. Ambos responden a diferentes avatares, desde el manuscrito al impreso, en la transmisión textual del teatro del último Lope. El interés por imprimir sus obras, que le había acompañado a lo largo de su carrera, podría decirse que se acentúa desde 1621, no solo ese mismo año con las publicaciones de las Partes XV-XVII, y luego XVIII (1623), XIX (1624), XX (1625), y las dos últimas Partes XXI-XXII, impulsadas por el autor y su círculo próximo, impresas el mismo año de su muerte,

1. Las siguientes consideraciones se inscriben en el proyecto de investigación H2019/HUM-5898 de la Comunidad de Madrid/Unión Europea (Fondo Social Europeo), adscritos al Instituto Universitario La Corte en Europa (IULCE). Las últimas circunstancias adversas durante la vejez de Lope, como la muerte de Marta de Nevares en 1632 o la fuga de Antonia Clara y la muerte de Lope Félix, el único hijo varón que le quedaba, en 1634, acentúan el tono elegíaco de su escritura, según pone de relieve Antonio Sánchez Jiménez [2018:311-341], en una biografía que culmina las de ilustres antecedentes desde Hugo A. Rennert y Américo Castro [1968], primera biografía rigurosa sobre el comediógrafo madrileño tras la Nueva biografía de Barrera [1880-1890]. Se inicia la serie en 1635, con la Fama póstuma de «su discípulo predilecto» (Trambaioli 2016:183), ya que gracias al testimonio de Juan Pérez de Montalbán conocemos de primera mano el transcurso de sus últimos días.

2. Cuenca Muñoz [2021] analiza las razones que le llevaron a modificar el primer testamento por su reciente pertenencia a la Orden de San Juan que le obligaba a cumplir los estatutos relativos a la herencia, tras el nombramiento otorgado por Urbano VIII que no fue efectivo hasta 1631, para dentro de ese cumplimiento favorecer lo más posible a su hija Feliciana como única heredera. 
sino también con la edición de poemarios como el atribuido a Tomé de Burguillos (1634), o bien como los Triunfos divinos (1625), los Soliloquios amorosos (1626), la Corona trágica (1627), el Laurel de Apolo (1630), o en colecciones como La Filomena (1621) y La Circe (1624), además de La vega del Parnaso (1637), en comedias sueltas como la barcelonesa de $E l$ castigo sin venganza (1634), o bien en prosa como $L a$ Dorotea (1632), todas ellas editadas durante la última etapa de su producción o incluso de su vejez.

En relación con las diferentes estrategias editoriales del último Lope, las siguientes consideraciones se plantean el significado que adquieren el mecenazgo y la búsqueda de prestigio literario para el comediógrafo madrileño, en función de los intereses cortesanos característicos de las sociedades europeas de aquella época, tomando como referencia en la segunda parte de la argumentación una obra teatral poco conocida o reconocida, el Diálogo militar, cuya edición fue incluida en La vega del Parnaso. De manera previa, se considera el interés por la publicación de su teatro, que, después de la prohibición durante diez años de imprimir comedias y novelas en el reino de Castilla, tras la publicación de las Partes XIX-XX, se mantuvo hasta la aparición de las dos Partes siguientes.

\section{De las Partes XXI-XXII a La VeGa}

La estrategia editorial que siguió Lope para consolidar su prestigio literario, como ha insistido el lopismo actual una y otra vez, había hecho que el escritor madrileño desarrollase un verdadero programa individual de publicaciones, especialmente tras la primera suspensión de las representaciones teatrales en 1598, comenzando ese mismo año la edición de tres de sus primeras obras, tanto en prosa como en verso: la Arcadia (1598), La Dragontea (1598) y el Isidro (1599). La voluntad de imprimir su variada producción literaria se hizo extensiva también a su poesía lírica, desde las sucesivas ediciones de las Rimas a partir de 1602, que continúa en la publicación de otros dos poemarios, las Rimas sacras (1614) y el mencionado de Tomé de Burguillos, editado un año antes de su muerte.

Aunque obtenía pingües ganancias económicas con sus comedias en verso, destinadas a la representación, por lo cual vendía sus autógrafos a los autores de comedias, Lope acabó también por asumir la publicación de su teatro en las deno- 
minadas Partes que habían sido iniciadas sin su permiso en 1603-1604. El éxito editorial hizo que aceptara su publicación, al menos, desde la Parte IV impresa en $1614,{ }^{3}$ si bien no firma de manera explícita las dedicatorias de los sucesivos volúmenes hasta la Parte IX de 1617, significativamente dirigida al duque de Sessa, en cuyo prólogo reivindica la autoría de sus comedias denunciando las deturpaciones textuales a que las sometían sus impresores.

Si el último Lope mantuvo el proyecto editorial de las Partes hasta el mismo año de su muerte, el de La vega del Parnaso mencionado ya en 1633 no sería publicado hasta cuatro años después. Además de codirigir su edición crítica, Felipe B. Pedraza se ha interesado sobre las posibles fases en la edición de este conjunto de composiciones poéticas y ocho comedias. Algunas de sus piezas fueron compuestas con posterioridad al año en el que se menciona por primera vez el proyecto, incorporando a este textos que, como la silva $A l$ Siglo de Oro y el soneto impreso tras ella que abre La vega donde elogia al portugués Gabriel Pereira, «no existían ni siquiera en la primavera o en los inicios del verano de 1635, cuando Lope tuvo que presentar la obra para la preceptiva censura y la obtención del privilegio». ${ }^{4}$ Se observa con claridad en el volumen, considerado como el auténtico testamento literario del último Lope, la divergencia aludida entre el legado póstumo de su azarosa fortuna editorial y la interrupción de la vida del escritor.

El afán por acceder a la imprenta, en todo caso, resultaba excepcional en la época como se comprueba nada más comparar el entusiasmo de Lope y la contención editorial de un Góngora o de un Quevedo a la hora de imprimir sus respectivas obras. Sin embargo, resulta más controvertida la valoración por parte de la crítica de las estrategias editoriales adoptadas por Lope, que han llegado a ser consideradas en lo que llevamos de milenio como muestra de una temprana profesionaliza-

3. Véase Gómez [2000:12], como se deduce del epistolario de Lope, quien supervisa, con la complicidad de Gaspar de Porras o Porres, la Parte IV cuando le escribe al duque de Sessa en mayo de 1614, Cartas, p. 283: «Diome el libro e las Comedias, y dijo que le había presentado a vuestra excelencia». Además, pleitea sin éxito con el mercader Francisco de Ávila, quien había obtenido el privilegio real para publicar las Partes V y VI, impresas en 1615, por los derechos de las comedias luego publicadas en las Partes VII y VIII de 1617, como señala Moll [1995:220-221].

4. Véase Pedraza [2014:28], quien argumenta la hipótesis de un poemario inicialmente sin las ocho comedias que serían añadidas en una segunda fase, a instancias del sacerdote amigo José Ortiz de Villena, después de la muerte del comediógrafo, frente a la hipótesis de Maria Grazia Profeti cuando sostiene que las ocho comedias formarían parte del texto supervisado por el escritor. El mismo Pedraza [2015:I, 29] afirma: «con los datos de que hoy disponemos, no es posible descartar ninguna de las dos hipótesis». 
ción del oficio de escritor y de la comercialización de su escritura, anticipando casi en dos siglos la autonomía de las «reglas del arte», en términos que el sociólogo francés Pierre Bourdieu [1992] aplicó a la específica configuración decimonónica de un mercado artístico, muy posterior al mecenazgo predominante en la sociedad cortesana de los siglos XVI y XVII.

Las aspiraciones de Lope para integrarse en el mismo sistema asociado al amateurismo nobiliario y el ideal del otium literario se minusvaloran cuando se entienden (Gómez 2021) como históricamente subordinadas a los valores posteriores que exaltan la profesionalización y laboriosidad burguesas. Porque la búsqueda tanto del clientelismo como del mecenazgo se mantiene con especial intensidad en el Lope de senectute, según la formulación acuñada por Rozas para el periodo que va desde el año de su primer testamento en 1627 hasta su muerte, durante el cual obtiene el título de caballero del hábito de San Juan otorgado ese mismo año por Urbano VIII, un reconocimiento eclesiástico que debió de compensarle en algo de su frustración por no acceder al puesto de cronista real y, en general, del «desvío de Palacio para con Lope» (Rozas 1990:124). ${ }^{5}$ Condicionan estas aspiraciones tanto nobiliarias como eclesiásticas las dedicatorias de sus obras a los sucesivos mecenas y la escritura de las representaciones cortesanas, cuya tradición de mecenazgo bajo la protección de la corte o de los círculos nobiliarios coexiste, de manera complementaria, con la producción teatral inicialmente destinada a los corrales de comedias.

Desde la mencionada Parte IX (1617), la publicación de los sucesivos volúmenes de doce comedias se mantuvo bajo supervisión del comediógrafo a muy buen ritmo: doce volúmenes en ocho años, hasta que se vio interrumpida después del vigésimo, en 1625, por la medida de la Junta de Reformación en marzo de ese año prohibiendo que se publicase novelas y comedias en el reino de Castilla. Lo que provocó que continuase la serie publicando comedias de Lope y de otros autores «en los reinos de la Corona de Aragón o con pies de imprenta falsos de ciudades de dichos reinos, pero en realidad obra de imprentas de los reinos de Castilla, principalmente de impresores

5. Aunque Rozas [1990:126] señala que «Lope, desde junio de 1631, con La noche de San Juan, no recibió encargos palaciegos», El Amor enamorado se escenificó en los jardines del palacio del Buen Retiro entre mayo y junio de 1635. Por su parte, Ferrer [2013] documenta la significativa presencia de comedias de Lope representadas en palacio, bien por encargo, como el Diálogo militar y otras del último Lope: La selva sin amor, La noche de San Juan o El Amor enamorado, donde se atestigua su insistente afán de mecenazgo, o bien las comedias del corral representadas como particulares en la corte, también con éxito. 
sevillanos» (Moll 1974:101). ${ }^{6}$ Después de reanudarse la concesión de licencias, con el privilegio de marzo de 1635 concedido a Tirso de Molina para la Parte IV de sus comedias, se solicita la publicación de las Partes XXI y XXII de Lope que, con la intervención de amigos, como el también sacerdote José Ortiz de Villena, y familiares, como su yerno Luis de Usátegui y su hija Feliciana, continuaban la serie precedente el mismo año de la muerte del dramaturgo: la XXI con privilegio de 25 de mayo, en la imprenta de la viuda de Alonso Martín, y la XXII con privilegio de 21 de junio, en la imprenta de la viuda de Juan González; la primera costeada por el librero Diego Logroño y la segunda, por Domingo de Palacio y Pedro Vergés.

Casi una década antes el mismo Lope había hecho ya el intento de solicitar sus respectivas aprobaciones, el día 6 de marzo de 1626, según consta en un memorial de petición de licencia, aunque no se dio entonces permiso para imprimirlas. ${ }^{7}$ Por tanto, cabe matizar la afirmación de Maria Grazia Profeti [1997:14]: «es una pena que no pudiera ver impresas las Partes $X X I-X X V$ que había preparado después del levantamiento de la prohibición misma, a finales de 1634». Aunque pueda haber errores en el texto de las comedias, los dos primeros volúmenes del comediógrafo que aparecen de manera póstuma responden a la misma estrategia editorial interrumpida bruscamente diez años antes.

Otra cuestión es hasta qué punto Lope, o alguno de sus albaceas, modificó el texto y la nómina de comedias que integraban originalmente las Partes XXI-XXII desde que el comediógrafo solicitó su aprobación en 1626 de manera infructuosa. Si hacemos caso a la fecha de composición establecida de manera general a partir del catálogo de Morley y Bruerton [1968], se habrían añadido algunas como La boba para los otros (c. 1630), El castigo sin venganza y La noche de San Juan (1631) en la Parte XXI verdadera de Lope, o La vida de S. Pedro Nolasco (1629) y No son todos ruiseñores (c. 1630) en la XXII perfeta de Lope, como son calificadas respectivamen-

6. La prohibición dio lugar a continuaciones no autorizadas, donde se incluían comedias que no eran de Lope, conocidas como colecciones de diferentes autores, de acuerdo con el catálogo de Profeti [1988].

7. Como puntualiza Bouza [2011:351-355], al denegar la petición el Consejo advierte sobre la existencia de otras Partes XXI y XXII, contrahechas con sendos pies de imprenta falsos a partir de la Parte XX impresa por la viuda de Alonso Martín en 1625. Diez años más tarde, además de solicitar los privilegios de las dos partes citadas XXI y XXII en 1635, pidió Lope una tercera licencia también en 25 de mayo para un volumen que no llegó a imprimirse de doce comedias, todas ellas anteriores al último Lope: «impresas anteriormente, nueve en partes no controladas por Lope y tres en las que él no publicó», como señala Moll [1992:201]. 
te en sus portadas para diferenciarlas de las colecciones extravagantes o de varios y diferentes autores. ${ }^{8}$

La mayoría de las comedias restantes en ambos volúmenes de 1635, teniendo en cuenta la variación en los intervalos de sus respectivas fechas de composición, corresponde a la década de los veinte. De la Parte XXI: La bella Aurora (1620-1625), iAy, verdades, que en amor...! (1625), El mejor alcalde, el rey (1620-1623), El premio del bien hablar (1624-1625), El piadoso aragonés (1626), Los Tellos de Meneses I (16201628), Por la puente, Juana (1624-1625); y de la Parte XXII: Quien todo lo quiere (1620), Amar, servir y esperar (1624-1635), La primera información (1620-1625), Amar sin saber a quién (1620-1622), El labrador venturoso (1620-1622), Los trabajos de Jacob (1620-1630), La carbonera (1623-1626) y Amor, pleito y desafio (1621). ${ }^{9}$

Sin embargo, el modus operandi varía desde la Parte XXIII, editada en 1638 a costa de Pedro Coello, en la imprenta de María de Quiñones, aunque su privilegio fuera solicitado por Usátegui, sin que conste la supervisión del comediógrafo, entre cuyas doce comedias predominan aquellas que corresponden por su composición a fechas anteriores a las del último Lope, tanto si tomamos como referencia cronológica la subida al trono de Felipe IV en 1621, como si aceptamos el año a quo de su primer testamento en $1627 .{ }^{10}$ Algo similar sucede en las Partes XXIV (1641) y XXV

8. Como señala Zapatero Molinuevo [2020:45]: «Tanto Logroño como Ortiz de Villena, ambos figuras influyentes en la herencia editorial de Lope, estuvieron presentes en la víspera de la muerte del dramaturgo y ejercieron como testigos cuando otorgó testamento ante el notario Francisco de Morales y Barrionuevo. Junto a ambos, la tercera figura de relevancia en la impresión de la Parte XXI y en estos últimos días de la vida de Lope fue Luis de Usátegui, yerno de Lope, casado en 1633 con su hija Feliciana y oficial de la secretaría del Consejo de Indias, que actuó también de albacea literario junto a Ortiz de Villena y que sería el encargado de proporcionar el plan editorial para las Partes XXI, XXII y La vega del Parnaso con la ayuda de este último y, ya sin Ortiz de Villena, el de la Parte XXIII»,

9. Se exceptúa, en la Parte XXI, Los bandos de Sena (1597-1603) y La victoria de la honra (16091612); en la Parte XXII, Nadie se conoce (1615-1621) y La mayor victoria (1615-1624). A pesar de estar supervisada por el círculo próximo a Lope, sorprendentemente en la Parte XXII, la comedia Amor, pleito y desafío no se corresponde con el autógrafo de 1621, sino con la Parte XXIV extravagante de Lope (y otros), publicada en Zaragoza, 1633, correspondiente al texto de Ganar amigos de Ruiz de Alarcón, según advierte Dixon [1996:60]: «El error sugiere que Lope no pudo haber mirado de cerca el texto para pedir el privilegio».

10. Según el catálogo de Morley y Bruerton [1968], de las doce comedias de la Parte XXIII, seis son de autoría dudosa o incierta: Contra valor no hay desdicha (1625-1630), Las cuentas del Gran Capitán (1614-1619), Porfiar hasta morir (1624-1628), El robo de Dina (1615-1622), El saber puede dañar (1620-1625) y El saber por no saber (c. 1620), mientras que las de autoría segura se datan con anterioridad a la década de los veinte: Las Batuecas del Duque de Alba (1598-1603), El piadoso veneciano (1599-1608), La envidia de la nobleza (1613-1615), Los pleitos de Ingalaterra (c. 1604), Los palacios de Galiana (c. 1602) y Dios hace reyes (1617-1621). 
(1647), si bien aparecen de nuevo, para diferenciarlas de las extravagantes, con el calificativo de perfeta, cada una de ellas, en sus respectivas portadas.

Consideradas habitualmente como el final de las Partes auténticas de las comedias lopescas, fueron impresas en Zaragoza: la XXIV por el impresor zaragozano Pedro Vergés, a costa de su homónimo librero madrileño; y la $X X V$, por la viuda del impresor Pedro Vergés, a costa del librero Roberto Deuport, más conocido como Duport. Sin embargo, en ambas escasean las comedias auténticas fechadas a partir de la década de los veinte, como El caballero de Olmedo (1620-1625) y La nueva victoria de don Gonzalo de Córdoba (1622) en la XXIV, o Lo que ha de ser (1624) y El desprecio agradecido (c. 1633) en la XXV perfeta y verdadera. En cambio, predominan de manera absoluta las datadas con anterioridad y hay algunas, como Los embustes de Fabia (1588-1595) en la XXV, caracterizadas por la irreverencia propia del primer Lope. ${ }^{11}$ De este modo el proyecto editorial de las Partes se vería definitivamente alterado después de 1635, con o sin mediación de albaceas literarios próximos a Lope de Vega, por la divergencia entre la «muerte del autor», nada metafórica ni hermenéutica en este caso, y el legado póstumo de su obra.

Se ha llegado a plantear la crítica, como hace Antonio Carreño [2020:259], si el último Lope «está de vuelta del teatro» y si, después de su primer testamento en 1627, se afianza «su conciencia de senectud y la decisión de alejarse de las tablas del corral». Hemos comprobado que, por las fechas de composición de las comedias allí reunidas, las Partes XXI y XXII manifiestan el interés del comediógrafo por

11. En la Parte XXIV, son de dudosa autoría La hermosa fea (1630-1632), Guardar y guardarse (1620-1625), si bien según Morley y Bruerton [1968:473]: «La comedia es de Lope», como lo serían: El servir a buenos (1620-1625), La ilustre fregona (¿1619?), El nacimiento de Cristo (1597-1600) y Los peligros de la ausencia (1615-1618), mientras que se datan con anterioridad a la década de los veinte las comedias de Lope: El bastardo Mudarra (1612), Los Ramírez de Arellano (1604-1608), S. Nicolás de Tolentino (c. 1614) y Barlaán y Josafat (1611). Que la impresión de esta Parte estuviera fuera de control reforzaría la hipótesis de que la jornada tercera de la última comedia mencionada en su versión allí editada no es de Lope, como sostiene Crivellari [2021a], a quien se debe la reciente edición crítica de la misma comedia [2021b]. En la Parte XXV son de dudosa autoría La esclava de su galán (c. 1626), si bien: «parece definitivamente de Lope» según Morley y Bruerton [1968:460], Los cautivos de Argel (c. 1599) y La necedad del discreto (c. 1613), mientras que son anteriores a la década de los veinte las siguientes comedias de Lope, además de Los embustes de Fabia: El último godo (1599-1608), El juez en su causa (c. 1610), El mayor imposible (1615), La nueva victoria del marqués de Santa Cruz (1604), Castelvines y Monteses (1606-1612) y la segunda parte de Don Juan de Castro (c. 1607-1608), originalmente publicada en la Parte XIX (1624) y luego incluido en esta parte con un título modificado: Las aventuras de don Juan de Alarcos, sobre cuya fiabilidad textual ha llamado la atención Rodríguez-Gallego [2020]. 
reunir obras pertenecientes a su última producción dramática, a partir de la década de los veinte, con una coherencia que por diversas razones la crítica ha percibido en las Partes supervisadas por Lope antes de la prohibición para imprimirlas en el reino de Castilla, como hizo Florence d'Artois [2009] al preguntarse sobre los posibles criterios internos al seleccionar las comedias de una parte, cuyo resultado dependería de factores prácticos y aleatorios a la hora de conseguir los manuscritos originales, pero que podrían responder a una determinada voluntad autoríal. ${ }^{12}$

El mismo proyecto de PROLOPE ha venido dibujando durante las últimas dos décadas diversos criterios en cada una de las Partes supervisadas por Lope en la distribución y selección de comedias, como se percibe en la Parte XIX al hacer un balance del «proyecto editorial lopesco» que, junto a la «heterogeneidad inherente al formado de la parte adocenada», deja traslucir algunos hilos conductores que «responden a un plan autorial pensado con detalle de antemano», según advierten Alejandro García-Reidy y Fernando Plata [2020:I, 15]. Por tanto, una hipótesis sobre el final de la serie es que únicamente las Partes XXI y XXII, después de la muerte del comediógrafo, responden a la voluntad autorial de otros volúmenes supervisados por Lope con anterioridad a la prohibición de imprimir comedias.

Después de interrumpirse la serie de las Partes en 1625, sin embargo, el comediógrafo madrileño había tenido que diversificar la estrategia editorial con respecto a sus comedias, si bien la actividad teatral siguió ocupando un lugar privilegiado entre sus proyectos, como lo indica también el interés que manifestó hasta su muerte en controlar las Partes que habían gozado de un éxito individual sin precedentes, marcando la pauta del resto de comediógrafos para las ediciones de la comedia nueva. Según planteara Maria Grazia Profeti [1998:28-31], el Fénix adoptó una serie de estrategias editoriales para esquivar la prohibición de imprimir su teatro, como hace al promover la edición suelta impresa en 1634 de El castigo sin venganza editada en Barcelona por Pedro Lacavallería, luego incluida en la Parte XXI nada más reanudarse la serie interrumpida porque: «quería volver a publicar la que parecía

12. Concluye d'Artois [2009:292-293]: «En el caso del teatro de Lope, es imposible contemplar de la misma manera las primeras partes que se publicaron sin ser autorizadas por Lope -al menos de manera oficial- [...] y aquellas Partes cuya publicación fue supervisada, al contrario, por el mismo dramaturgo (de la Parte $I X$ a la Parte $X X$ ). En este segundo grupo de partes, la declarada voluntad de Lope de fijar el texto de sus obras y de tomar el control del proceso editorial de su teatro reduce el papel que pudieron tener los fines exclusivamente mercantiles en el proceso de conformación de las Partes». 
percibir como una de las cumbres de su repertorio", como afirman los recientes descubridores de otra suelta anterior (García-Reidy, Valdés y Vega 2021:277), publicada con el título Un castigo sin venganza, que es cuando Lope quiere, hasta ahora sin catalogar en la Biblioteca Nacional, impresa en Sevilla, hacia 1632.

También durante la suspensión, había publicado el Laurel de Apolo (1630), donde incluye una representación cortesana, La selva sin amor, escenificada en el Alcázar tres años antes con acompañamiento musical y escenografía del ingeniero florentino Cosme Lotti. Asimismo, publica en 1632 La Dorotea, una comedia en prosa en la tradición celestinesca de la comedia humanística, subtitulada como Acción con un evidente latinismo: actio, para subrayar el género teatral al que pertenece. No estaba destinada a la representación La Dorotea, como ocurría en las comedias para el corral usualmente compuestas en verso durante aquella época, sino a la lectura fuera de las tablas.

Según comenta el propio autor en el prólogo, aunque supuestamente firmado por su amigo Francisco López de Aguilar, era consciente de las manipulaciones a las que sometían los libreros andaluces sus comedias: «de Sevilla, Cádiz y de otros lugares del Andalucía, con la capa de que se imprimen en Zaragoza y Barcelona, y poniendo los nombres de aquellos impresores, sacan diversos tomos en el suyo", donde también se refiere al cansancio que le provoca la escritura para el corral de comedias: «que el papel es más libre teatro que aquel donde tiene licencia el vulgo de graduar». ${ }^{13}$ Quizá estaba un poco de vuelta el último Lope de las exigencias de su público y de las obligaciones editoriales derivadas de su incesante dedicación a la escritura dramática.

Sin embargo, no había dejado de escribir y publicar hasta su vejez comedias para ser representadas, aunque fuera lógicamente, por el peso de los años, a un ritmo menor que durante los periodos de su juventud y madurez creativas: Las bizarrías de Belisa datan de 1634 y, del año siguiente, la mencionada representación cortesana, El Amor enamorado, ambas también editadas de manera póstuma en $L a$ vega del Parnaso entre las ocho comedias allí reunidas, compuestas también entre las décadas de los veinte y treinta. ${ }^{14}$ Con independencia de que estas fueran añadi-

13. Lope de Vega, La Dorotea, pp. 94 y 92; véase Moll [1979].

14. Entre las ocho comedias reunidas en La vega del Parnaso, predominan las palatinas con ambientación pseudo-histórica más o menos próxima a los dramas históricos, como El guante de doña Blanca (1630-1635), La mayor virtud de un rey (c. 1634-1635) y iSi no vieran las mujeres! (1631- 
das tras la muerte del autor, enlaza su voluntad recopilatoria con las Partes $X X I$ y $X X I I$ por la estrategia común de reunir su última producción teatral legando su herencia al mercado lector. Está muy presente el interés por el teatro hasta los últimos años de Lope, incluso durante el periodo de senectute, según la denominación acuñada por Rozas, quien, quizá por basarse sobre todo en el tercero de los últimos códices poéticos que se conservan del Fénix: el denominado Códice Daza, para enlazar después de 1633 con las composiciones poéticas de La vega y Tomé de Burguillos, soslaya o minimiza su presencia: «Sabemos que Lope ganó considerables cantidades de dinero entre el mecenazgo y el teatro. Pero en este último ciclo de su vida casi no produce dramas» (Rozas 1990:129). ${ }^{15}$

Del recorrido biographico more propuesto por Rozas, se ha originado una serie de rasgos dentro de los cuales se incluye un abandono casi completo del teatro. Sin embargo, este desinterés no se corresponde con las estrategias editoriales sobre su actividad teatral que se observan todavía en torno al fallecimiento de Lope, o en su círculo próximo de albaceas y familiares, como ocurre en las Partes XXI-XXII, y también en La vega del Parnaso donde, por cierto, había incluido el mencionado Diálogo militar, que centrará la segunda parte de estas páginas. Perteneciente al subgénero del diálogo teatral, vamos a detenernos en esta obra por ser representativa de su última producción dramática, en relación con el mecenazgo y la preocupación del escritor por proyectar una determinada imagen pública acorde con la mentalidad predominante en la sociedad cortesana de su época.

1632), además de Porfiando vence amor (1624-1630), sobre las comedias urbanas, como El desprecio agradecido (c. 1633), incluida también en la Parte XXV, y Las bizarrías de Belisa (1634), ambas de ambientación madrileña, o sobre comedias mitológicas, como El Amor enamorado (1635), y militares, como La mayor victoria de Alemania de don Gonzalo de Córdoba (1622), incluida en la Parte XXIV con el título La nueva victoria de don Gonzalo de Córdoba.

15. Oleza [2003:603-604], al referirse a los nueve años últimos que Rozas llamó «de senectud», acepta que «Lope amenguó sensiblemente su dedicación al teatro (...), se podría calcular un conjunto de veintitrés obras, lo que significa un ritmo de dos obras y media por año. Sirve de referencia el período inmediatamente anterior, el que transcurre entre 1615 y 1626 , ambos años incluidos, y que no es ni mucho menos, el período de mayor producción de Lope: de él se conservan unas setenta y ocho comedias, lo que equivale a un ritmo de seis comedias y media por año». En su posterior recuento, García-Reidy [2013:172-174] calcula una cifra de 3,6 comedias por año para 1622-1635, frente a las 10 por año de su periodo de madurez, entre 1599 y 1621 . En cualquier caso, la progresiva disminución no implica desinterés por el teatro, si bien el hecho de que menos comedias sean destinadas al corral podría relacionarse con el incremento numérico de las compuestas para un público cortesano. 


\section{2. «DE SU MAJESTAD LE ESPERO»}

Tanto por su modalidad genérica como por su tratamiento de la materia histórica ocupa un lugar específico el Diálogo militar a honor del excelentísimo marqués de Espínola en la estrategia editorial de Lope de Vega, si bien Menéndez Pelayo, en sus todavía fundamentales Estudios sobre el teatro de Lope de Vega, originalmente publicados entre 1890 y 1913 como prólogo a la edición de las comedias lopescas en la Real Academia Española, lo agrupó indiscriminadamente después de las «crónicas y leyendas dramáticas de España» con tres comedias sobre asuntos de historia contemporánea: La nueva victoria del marqués de Santa Cruz (1604), El Brasil restituido (1625) y La nueva victoria de D. Gonzalo de Córdoba (1622), a pesar de que el Diálogo militar: «No es comedia, ni se intitula así» (Menéndez Pelayo 1949:VI, 249). Claro que el objetivo principal de sus estudios sobre las comedias históricas era establecer con la mayor certeza posible el grado de fidelidad de los sucesos dramatizados.

De hecho, subraya la continuidad de la historia nacional, como afirma Menéndez Pelayo [1949:VI, 253]sobre el protagonista del Diálogo militar, Ambrosio Espínola: «La noble figura del excelso hombre de guerra, expugnador de Ostende y de Breda, no es de las que se han borrado enteramente de la memoria de nuestro pueblo [...]: la musa juvenil de Calderón en El sitio de Bredá [...] completó lo que en el Diálogo [...] era un mero bosquejo». ${ }^{16}$ A diferencia del positivismo imperante en tiempos del santanderino, el vuelco actual de la historiografía tiende a problematizar la presunta objetividad de los testimonios históricos considerándolos como una representación cultural: «The ultimate belief that underlies many historical essays of the past fifty years in that our knowledge of the real is not a representation of the real, but a cultural construction» (Oleza 2012:76). ${ }^{17}$ Bajo este nuevo enfoque, antes que la grandeza histórica, se tiende ahora a subrayar su dependencia del mecenaz-

16. Regularizo la grafía y el acento llano del topónimo (Breda) excepto en los textos del Siglo de Oro donde mantengo la acentuación aguda entonces habitual. A diferencia del diálogo de Lope, la comedia de Calderón describe la batalla y el motivo de la entrega de las llaves que sirvió de inspiración a Velázquez, como ha estudiado S. Schreckenberg [2011]. En otras obras se basó Calderón para su comedia, como ha puesto de relieve Simon A. Vosters [1974:8-47]: las relaciones del capitán Alonso Vázquez y la Obsidio Bredana (1626) del jesuita Hermann Hugo, entre las cuales destaca una de las comedias flamencas de Lope, El asalto de Mastrique. Como Menéndez Pelayo, Vosters es partidario de una datación tardía del Diálogo militar entre los años 1628 y 1629.

17. De la Flor [2018:II, 99] analiza la «distancia abismal que puede haber entre los hechos militares y violentos, y lo que es la reconstrucción simbólica de tal violencia». 
go tan presente en La vega del Parnaso, donde fue incluido el Diálogo militar. Comparte, de hecho, con otras muchas obras allí agrupadas la necesidad de reconocimiento por parte no solo de la corte de Felipe IV, sino de otros nobles y poderosos.

La busca del mecenazgo hizo más por la exaltación del linaje de los Espínola que la imperecedera memoria popular invocada por Menéndez Pelayo, por lo menos antes de la inauguración en 1633 del palacio del Buen Retiro, donde se ambientaría el programa pictórico y visual del Salón de Reinos con el famoso cuadro de Velázquez, compuesto casi una década después del Diálogo militar, cuya datación sitúa Ferrer [2014] no muy lejos de la emblemática fecha de 1625, mientras que Rodríguez-Gallego [2015], en otro trabajo básico para la recuperación de la obra desde una perspectiva actual, mantiene la datación tradicional al retrasarla hasta $1628 .{ }^{18}$ La crítica, sin embargo, coincide en proponer una supuesta representación del diálogo realizada por encargo para celebrar las hazañas militares del linaje genovés, condensadas en una relación de casi trescientos versos (vv. 353-643) puesta en boca del soldado Julio como testigo de vista: «Vengo de Flandes; / halleme / en el sitio de Bredá, / adonde el marqués está / que ningún contrario teme» (vv. 185-188).

De este modo, enlaza su planteamiento belicista con el ciclo de comedias flamencas anteriores al último Lope que, como El asalto de Mastrique (1595-1606) y Los españoles en Flandes (1592-1606), dramatizan las victorias de las tropas de Felipe II en los Países Bajos como parte integrante de la Monarquía Hispánica: «esto implica que los enemigos son concebidos como rebeldes y no como herejes» (Usandizaga 2014:190). ${ }^{19}$ En la extensa relación del Diálogo militar el soldado Julio se refiere también a la revuelta de Bohemia que dio inicio en 1618 a la guerra de los Treinta Años tras la defenestración de Praga y el pleito por la elección imperial entre el protestante Federico V y el católico Fernando II, quien fue socorrido por sus parientes Habsburgo españoles. Nombrado capitán general, Espínola invadió en 1620 con un ejército de 25.000 hombres el Palatinado, en una exitosa campaña militar a la que alude el soldado Julio en su narración: «derribando la soberbia / del palatino, ganó / la más parte de su tierra» (vv. 540-542). El ejército a su mando contribuyó a la derrota de Federico V, proclamado rey de Bohemia en 1619, a cuya so-

18. Lope de Vega, Diálogo militar, pp. 283-347. Todas las citas del texto del diálogo provienen de esta edición, sin más que indicar entre paréntesis el número de versos.

19. Analiza Rodríguez Pérez [2008:95-126] la imagen negativa de los enemigos en las comedias flamencas de Lope. 
berbia contraria a la fe católica alude en la cita anterior, ya que coexisten los intereses políticos y religiosos con las alianzas dinásticas de los Austrias, a diferencia de aquellas comedias donde la disputa confesional aparece en primer plano.

Así, en La nueva victoria de don Gonzalo de Córdoba (1622), publicada póstumamente en la Parte XXIV de 1641 e incluida antes en La vega del Parnaso con un ligero cambio de título, subraya la dramatización de la victoria en Fleurus, por las tropas al mando del hermano del mecenas de Lope de Vega, el duque de Sessa, frente a la herejía de los derrotados luteranos: «Nosotros, a vencer hechas las manos, / ¿qué podemos temer? La fe nos guía, / y a estos bárbaros viles luteranos, / la codicia, ambición y herejía». ${ }^{20}$ Pero la visión providencialmente católica no aparece tan explícita en el Diálogo militar, al plantear el enfrentamiento con los rebeldes flamencos dentro de la propia Monarquía Hispánica, mientras que en Don Gonzalo de Córdoba insiste en el componente religioso de la guerra contra los protestantes alemanes.

Reaparece en primer plano la defensa de la religión católica en El Brasil restituido, comedia lopesca de la que conservamos su autógrafo datado en 1625, pero no incluida entre las partes, ya que no se llegó a editar hasta el siglo pasado. Después de la conquista holandesa de Salvador de Bahía en mayo de 1624 —un efecto colateral de las guerras de Flandes-, la colonia brasileña fue recuperada antes de un año por las tropas hispanoportuguesas al mando de Fadrique de Toledo, lo que explica su composición pocos meses después de la llegada a Madrid de la noticia. Este tipo de dramatizaciones militares formaba parte de la estrategia de Lope en busca del favor del todopoderoso conde-duque Olivares modulando en cada caso el significado de la victoria. ${ }^{21} \mathrm{El}$ Diálogo militar fue compuesto también en apoyo de la política olivarista, si bien su triunfo exalta el heroísmo individual de Espínola sobre «las islas» en alusión a las Provincias Unidas que rivalizaban con España con otras potencias enemigas: «Allí, admirándose Francia. / Temblaron Ingalaterra / y las islas, cuyo mar / estremeció sus riberas» (vv. 591-594).

20. Lope de Vega, La mayor victoria de Alemania (Ioppoli 2015:389), donde se pone de relieve la importancia que adquiere la causa protestante para Mansfelt y el obispo de Holstad quienes, después de haber servido al elector palatino Federico V, fueron contratados por los holandeses poco antes de la batalla de Fleurus.

21. Menéndez Pelayo [1949: VI, 247 y 225] acuñó a propósito de este subgrupo militar de «nuevas victorias» las calificaciones de "relación o gaceta dramática», así como la de "periodismo dramático». Por su proximidad a los hechos dramatizados, Pérez Rodríguez [2008:207-210] agrupa La nueva victoria y El Brasil restituido entre «the ocassional plays». 
En las comedias flamencas de Lope de Vega, diferencia Antonio Cortijo [2013:111-112] el heroísmo individual de los militares de alta graduación situados en un plano superior, pero secundario en la intriga, que «suele ofrecer personajes muy poco dibujados y narraciones extensas de sucesos bélicos», de un nivel inferior protagonizado por la soldadesca que asume una lealtad colectiva para «rendir tributo a una profesión y crear, al hacerlo, una imagen idealizada de la nación de la que el público se sintiera satisfecho». El contraste del heroísmo de la soldadesca española y el individual de Ambrosio Espínola se mantiene hasta la actualidad en la novela de Arturo Pérez Reverte, El sol de Breda de 1998, cuyo narrador concluye: «no éramos sino la carne de cañón, el eterno decorado sobre el que la otra España, la oficial de los encajes y las reverencias, tomaba posesión de las llaves de Breda» (El sol de Breda, p. 249). ${ }^{22}$ Se ha venido considerando la mitificación colectiva de la soldadesca, desde el Siglo de Oro, como respuesta a determinados estereotipos antihispánicos sobre la arrogancia y soberbia hispánicas. ${ }^{23}$ En esto también se diferencia de las comedias flamencas, ya que el contraste con la soldadesca es sustituido en el Diálogo militar por la dualidad entre un marco cortesano imaginario y la relación de carácter histórico sobre Espínola.

El soldado Julio, quien actúa de vínculo entre la historia y la ficción del Diálogo militar, se encuentra en las proximidades del Alcázar madrileño con la ninfa Marbela y sus dos hermanas, Amarilis y Gerarda, ante las cuales hace su narración donde conmemora los triunfos de la nobleza española y sus aliados ya que, como señala Joan Oleza [1997:xl]: «Buena parte del teatro histórico de Lope no tiene por objetivo tanto el contar lo que ocurrió 'en verdad' como el celebrarlo». Un propósito celebrativo que viene justificado, en el caso del Diálogo militar, por el imaginario cortesano que enmarca la relación inspirada en el Título perpetuo del marqués de los Balbases que Felipe IV otorgó al genovés Ambrosio de Espínola en 17 de diciembre de 1621, como ha puesto de relieve Fernando Rodríguez-Gallego [2016] cuando coteja las semejanzas textuales del Título con la relación del Diálogo militar.

22. El narrador de Pérez Reverte, según Rodríguez Pérez [2008:279-280]: «explicitly opposes the idealised representation of Spanish magnanimity and superiority displayed by glorified nobleman and high-ranking officers. The hard-won victory is due to the ordinary soldiers of the Tercios».

23. Como propone Sánchez Jiménez [2016], en la senda de trabajos anteriores de Rodríguez Pérez, Sánchez Jiménez y Den Boer [2015], o de Rodríguez Pérez y Sánchez Jiménez [2016]. 
Además de celebrar las hazañas bélicas de los Espínola que culminan en la victoria de Breda, el marco cortesano del Diálogo militar exalta el reinado «del claro sol de España» (v. 48), como afirma la ninfa Marbela con una imagen solar que reaparece más tarde en boca del soldado Julio «...el cuarto Felipe, / el sol de la cuarta esfera» (vv. 569-570). Aunque la invocación de la ninfa a la diosa de la Paz pudiera resultar paradójica, el diálogo celebra no tanto la victoria militar como sus consecuencias. Lope de Vega lo compone durante la fase triunfal de Olivares, en un periodo de éxitos bélicos previo al giro de los acontecimientos, cuando la misma ciudad de Breda fue reconquistada por los holandeses en 1637, ya que el cambio adverso culminó el mismo año de la muerte del comediógrafo en la declaración de guerra de Francia a España. ${ }^{24} \mathrm{El}$ contexto previo a la intervención francesa explica el tono victorioso en el Diálogo militar.

Al final de su relación sobre Espínola, exclama el soldado: «iOh venusino famoso!, / joh Virgilio!, si vivieras / para escribir la vitoria / que le ha de dar fama eterna / con el sitio de Bredá» (vv. 581-585). La invocación de Julio reivindica el papel del escritor que pretende de manera incansable el reconocimiento cortesano, como afirma Teresa Ferrer [2014:179] al identificarlo estratégicamente con otra máscara de Lope de Vega: «El elogio se proyecta sobre el propio Lope, que se presenta así indirectamente cual otro Virgilio, bajo la máscara del soldado Julio». Su disfraz de soldado, con la habitual vestimenta caracterizada por su vistosidad y colorido: Sale Julio, soldado, con muchas plumas, banda roja y botas y espuelas, de camino, encubriría irónicamente el propósito del dramaturgo en busca de mecenazgo: «Voy a la corte del sol» (v. 133). Un motivo que se integra en el teatro lopesco para ensalzar la función de su escritura como resultado del agradecimiento cortesano: «que esto entretener ha sido / las musas un breve rato, / que más culpa es ser ingrato / que el errar agradecido» (vv. 771-774).

Las representaciones cortesanas se componían para ser escenificadas ante un círculo selecto de nobles y personajes principales, como varias comedias del último Lope concebidas para los Reales Sitios, desde El vellocino de oro, editada en la Parte XIX y cuya escenificación en los jardines de Aranjuez se vio interrumpida en mayo de 1622 por un incendio, pero que fue representada en otras ocasiones vinculada a la casa de Austria, hasta El Amor enamorado que, inspirada en el mito de

24. La crisis de Mantua anticipó el enfrentamiento que habría de alterar la «gran estrategia» de Olivares: «La confesionalidad parecía que dejaba de ser la directriz de la guerra, y ello provocó confusión y desconcierto» (Manuel Rivero 2017:239). 
Apolo y Dafne, había sido incluida en La vega y escenificada en los jardines del Buen Retiro en 1635. ${ }^{25}$ Son característica de ellas la temática mitológica, muy presente en el teatro del último Lope, quien hasta 1621 «no publicó la primera de sus comedias mitológica, pero en este año entregó de golpe a la imprenta cuatro piezas del género, que aparecieron juntas en la Parte XVI» (Sánchez Aguilar 2010:29). ${ }^{26}$

La mitología sirve de inspiración a diversas alusiones del Dialogo militar como cuando Marbela se compara con la ninfa Dafne (v. 60) y desea consagrarse a Diana (v. 70). Su disfraz alude a una realidad cortesana localizada bucólicamente cerca del Manzanares: "Yo soy, Paz, una ninfa / de estas selvas sagradas; / un río siempre humilde / hija suya me llama» (vv. 42-43). Precisamente por estar ambientado a orillas del Manzanares y por su corta extensión, se acerca el Diálogo militar a otra representación cortesana del último Lope de ambientación mitológico-pastoril ya mencionada por haber sido editada en el Laurel de Apolo en 1630, La selva sin amor, aunque su puesta en escena tres años antes había resultado mucho más espectacular (Sáez Raposo 2018:94-104).

Se asemejan las dos piezas por su corta extensión, ya que la acción del Dialogo militar se desarrolla en 780 versos. El esquema argumental básico del diálogo teatral remite al encuentro del caballero con la pastora característico de la pastorela, si bien la intriga amorosa aparece muy poco desarrollada porque los requiebros iniciales de Julio chocan con el rechazo de la ninfa, sin intervención de pastores ya que, a diferencia de La selva, el Diálogo militar no puede considerarse como égloga teatral. ${ }^{27}$ Afirma Marbela: «aborrezco a los soldados» (v. 150), si bien vence su inicial

25. Ferrer [1996] y Gómez [2013:53-58]. Documentan Varey y Shergold [1989:235] otra representación de El vellocino dorado antes del 9 de octubre de 1626: «fecha de la orden de pago», que habría tenido lugar en presencia de la reina Isabel, mientras que Rodríguez [2020:543-545] recuerda el montaje posterior ante la nueva reina María de Austria, cuando después de su matrimonio por poderes con Fernando II de Hungría y Bohemia se reunió dos años después en Viena en 1631, si bien su escenificación fue aplazada en varias ocasiones hasta julio de 1633, todavía con Leonor de Pimentel en el reparto; así como otra posible puesta en escena cortesana de 1649, esta vez en el Milanesado, donde Mariana de Austria se dirigía a casarse con su tío Felipe IV.

26. Adonis y Venus, Las mujeres sin hombre, El Perseo y El laberinto de Creta. Sin embargo, después de El marido más firme, El vellocino de oro y La bella Aurora, no conservamos comedias mitológicas suyas entre 1625 y 1635, en coincidencia con la prohibición de imprimir obras dramáticas según señala también Sánchez Aguilar [2010:29].

27. A pesar de cierta ambigüedad en las denominaciones: «ninfa o serrana» (v. 129), pero también «pastora hermosa», para Marbela, mientras que sus dos hermanas son «serranas» (v. 255), las tres son calificadas en el Diálogo militar (p. 303) como «ninfas» desde su mismo dramatis personae. Además de la temática mitológica, se podría pensar que otra de las características propias del teatro 
rechazo gracias a la discreción cortesana de Julio. El tópico negativo sobre la soldadesca se reaviva tras la llegada de sus dos hermanas porque, aunque Gerarda se muestra amable, Amarilis desdeña sus costumbres: «porque nunca me pagué / de soldados fanfarrones» (vv. 301-302).

A diferencia de las comedias de Lope, el Diálogo militar deriva del subgénero del diálogo teatral presente desde la tradición renacentista, como en el Diálogo del nacimiento de Torres Naharro, con el que comparte varias semejanzas genéricas determinadas por su corta extensión y el estatismo de la acción dramática. Ambos poseen un número similar de versos, ya que el Diálogo del nacimiento tiene 777 (sin tener en cuenta la Adición), un número reducido de cuatro personajes (si tenemos en cuenta la Adición), con una distribución de papeles que tiene poco o nada que ver con la tipología habitual de la comedia. Por último, la introducción de extensos parlamentos también resulta propia del diálogo teatral porque, frente a la comedia, predomina el estatismo de la trama con un desarrollo argumentativo.

El Diálogo militar gira en torno a la desconfianza que sienten las ninfas ante las pretensiones del soldado en la corte de los Austrias. De acuerdo con la imagen habitualmente negativa del pretendiente, Julio se ve en la obligación de explicarles a las tres hermanas el motivo de su llegada para justificar su petición de mercedes. ${ }^{28}$ La broma de la desdeñosa Amarilis con la dilogía sobre la denominación de la fina tela para hacer camisas y su procedencia geográfica: «Si vos habéis visto a Holanda, / en camisas pudo ser» (vv. 683-684), antes que menoscabar la credibilidad del soldado, supone un nuevo guiño a esa máscara negativa del pretendiente cortesano. Porque el recelo que siente Amarilis ante la llegada del soldado justifica argumentativamente la muestra de «discreta cortesía» (v. 322) que ofrece Julio al hacer su relación sobre el linaje de los Espínola, con la que acaba convenciéndolas. Después de que Amarilis acceda a darle los brazos (v. 727), las tres le invitan a cenar con ellas para celebrar la victoria.

cortesano es la búsqueda de fórmulas alternativas a la comedia, como la del Diálogo militar o la de El vellocino de oro. Aunque esta «invención» adapta con toda probabilidad una comedia previa concebida para el corral, Martínez Berbel [2003:271] califica su peculiar estructura como «espectáculo palaciego de corta extensión».

28. Como afirma Brioso Santos [2020:187]: «El tema soldadesco puede ir unido al motivo de la pretensión cortesana, sobre todo en la novela, pero también en otros géneros: muchos hidalgos y caballeros pobres y provincianos se alistaban y bastantes de ellos terminaban como soldados rotos pretendientes, que, después de una carrera militar, aspiraban a recompensas o pensiones, el estilo de Miguel de Cervantes, por ejemplo». 
Junto con su específica estructura dialogada, el sentido celebrativo del Diálogo militar introduce un banquete conmemorativo que se inscribe en los fastos de la vida cortesana, «cuyas características básicas van a ser o bien su dependencia de circunstancias políticas y hechos famosos, que conmemoran, o bien la teatralización de rituales cortesanos» (Oleza 1984:21). Según se deduce del propio desenlace, este daría paso a la cena aludida en repetidas ocasiones a lo largo de la representación (vv. 698, 702 y 762) que precedería al banquete: «iOh, cuánto contento y gloria / a nuestros padres daremos / cuando juntos celebremos / del marqués la dulce historia!» (vv. 739-742). Formaría parte el encargo del Diálogo militar de una celebración próxima al círculo de los Espínola para obtener el reconocimiento o las mercedes del monarca.

Al finalizar su relato, el soldado se dirige a la hija de Espínola, que fue dama de Isabel de Borbón desde $1622 .{ }^{29}$ La celebración de la parte femenina del linaje genovés contiene la siguiente petición a los monarcas sobre Policena Espínola: «que de los reyes espera / felicísimo himeneo» (vv. 654-655). ${ }^{30} \mathrm{Si}$ aceptamos una datación anterior a 1626, cabe entender la propuesta matrimonial del diálogo como una incitación para conceder una recompensa al linaje de Espínola con la boda de su hija. Porque el imaginario cortesano del marco dramatizado en el Diálogo militar celebra los senderos de gloria de los Espínola y de Ambrosio, convertido a instancias de los archiduques de los Países Bajos españoles de banquero en militar, cuando su reputación había comenzado tras el sitio de Ostende que en 1604 le hizo famoso.

Las hazañas militares que refiere el soldado Julio no van más allá de 1621, ya que su relación depende del Título perpetuo de marqués de la villa de los Balbases, por lo que hay un salto cronológico desde la victoria de Montaña Blanca en 1620 hasta el resonante éxito de Breda. ${ }^{31}$ Si la contemporaneidad de los acontecimientos refe-

29. Se puede deducir incluso que la dama de la reina estuvo presente entre los espectadores cortesanos porque, después de haber mencionado a sus hermanos Felipe y Agustín, afirma el soldado: «Mas ya desde el gran palacio / una dama de la reina, / hermana suya, me llama» (vv. 643-645).

30. Lope de Vega en una de sus cartas a su protector el duque de Sessa, datada en 1628, le informa sobre la inminente boda del sobrino de Olivares, Diego Messía, con la hija de Espínola, y poco después se refiere al convite nupcial sin aludir a su pieza teatral, como aduce Ferrer [2014:178] cuando defiende una composición temprana del diálogo, previa al inicio de las negociaciones de la boda en 1626 .

31. Ni tan siquiera alude Julio en su relación a las conquistas alemanas de Espínola que tuvieron lugar entre 1621 y 1625, como la famosa rendición de Jülich en 1622 que, además de ser el motivo de uno de los doce cuadros de batallas (Rendición de Jülich, 1634) para el Salón de Reinos, inspiró el ciclo pictórico compuesto para una villa genovesa, como estudia José Luis Colomer [2002], 
ridos aproxima el diálogo a las dramatizaciones de las «nuevas victorias» como la de Gonzalo de Córdoba, incluida en La vega del Parnaso y en la Parte XXIV, su específico subgénero teatral, con la ambientación mitológica y clasicista, modula su propósito cortesano, diferenciado de las comedias bélicas. No se percibe en el Diálogo militar una concepción providencialista y nacionalista de la historia, que suele atribuirse en su conjunto al teatro de Lope de Vega de manera exagerada, quizá como herencia todavía del enfoque adoptado por Menéndez Pelayo. ${ }^{32}$ En cambio, la llegada del soldado Julio escenifica el afán de mecenazgo característico de la sociedad cortesana de la que participaban tanto el propio escritor madrileño como los Espínola.

No todo fue en aquella época luchar contra los herejes, teniendo en cuenta que existía una diversidad política entre la serie de conflictos conocida como la guerra de los Treinta Años: «la realidad fue otra: la alianza con los ingleses, la paz con los holandeses o con determinados príncipes alemanes, o la guerra contra ellos, no fue solo el resultado de un combate contra la herejía» (Usunáriz 2013:214). También el desarrollo de su teatro se entiende mejor históricamente de acuerdo con el sistema político y cultural propio de la sociedad cortesana, más que por una temprana profesionalización dependiente del mercado teatral. Según la interpretación aquí propuesta, su trayectoria como escritor se gobierna de manera predominante por la lógica del mecenazgo, que se acentúa en el teatro del último Lope, como se observa en el Diálogo militar. Tras oír el relato histórico del soldado, afirma Gerarda sobre la llegada a la corte de Julio: «por que en ella premio os den» (v. 673), a lo que replica el soldado: «De su majestad le espero» (v. 674).

\section{Conclusiones}

Aunque el modelo básico del arte nuevo sea el destinado al corral, con cuya comercialización podían obtener grandes beneficios económicos los comediógrafos de éxi-

mientras que Sanz Ayán alude al elogio de Espínola en el Diálogo militar por su capacidad bélica «mientras el potencial económico del poderoso genovés solo se menciona al describir su liberalidad» [2015:234].

32. Álvarez Junco [2001:314] se refiere al teatro lopesco: «uno de los más ardientes defensores de esta imagen oficial de un pueblo fundido con el monarca en la providencial misión de defender a la Iglesia», mientras que G. Usandizaga [2014:17-36] valora el impacto de los estudios de Menéndez Pelayo en la crítica contemporánea sobre Lope como dramaturgo de la historia. 
to, con el propio Lope a la cabeza, no se trata de un problema cuantitativo, sino de prestigio literario y del horizonte nobiliario de expectativas del que participaban los escritores de la sociedad cortesana, en cuanto aspiraban a integrarse en ella. Dicho sea, lo anterior, sin entrar ahora en el fondo de un debate, todavía pendiente en el hispanismo actual del Siglo de Oro, entre la profesionalización y la cortesanización (Gómez 2021) que, por decirlo con este último neologismo, se manifiesta de manera creciente en las estrategias editoriales del último Lope.

De cualquier modo, la escritura del teatro específicamente cortesano, por estar destinado a los Reales Sitios y por ser encargos palaciegos como el Diálogo militar, no entra en contradicción con la práctica escénica comercial, como si solo esta fuera verdaderamente novedosa y la otra, una rémora del escritor aficionado. Como vasos comunicantes, entre la práctica escénica cortesana y la comercial se producen trasvases continuos desde la corte al corral de comedias, y viceversa.

$\mathrm{Al}$ analizar el Diálogo militar, hemos visto que se pueden establecer también conexiones en el tratamiento de la temática bélica entre las piezas compuestas por encargo para el palacio y las comedias flamencas como El asalto de Mastrique y Los españoles en Flandes. Más allá de las diferencias condicionadas por los respectivos subgéneros teatrales, las similitudes se intensifican cuando comparamos el diálogo con las comedias militares de asunto contemporáneo, compuestas por las mismas fechas, en torno a otros episodios bélicos que formaron parte de la denominada guerra de los Treinta Años, como La nueva victoria o El Brasil restituido, con una intencionalidad parecida en apoyo de la política olivarista, durante la etapa triunfante del reinado de Felipe IV.

Claro que la cortesanización puede manifestarse de múltiples maneras, y no solo en el teatro específicamente cortesano como el Diálogo militar. En un trabajo paralelo a este, todavía en preparación, sobre el espacio cortesano en las comedias madrileñas de Lope de Vega, estoy analizando el desarrollo desde sus ejemplos más tempranos: El mesón de la corte (1588-1595) y Las ferias de Madrid (1588), a través de comedias ya de madurez que, como La discreta enamorada (1606) y El acero de Madrid (1607-1609), inauguran el «nuevo modelo de comedia urbana madrileña» (Arata 2000:24), donde adquieren centralidad espacios como la famosa huerta del palacio del duque de Lerma o el Paseo del Prado, hasta culminar en la plena cortesanización del último Lope, en La noche de San Juan (1631) compuesta para ser escenificada en los jardines del conde de Monterrey, cuñado de Olivares, pero tam- 
bién en Las bizarrías de Belisa (1634), destinada al corral. ${ }^{33}$ Porque la preponderancia del espacio cortesano representado se produce también en la variante teatral de la comedia urbana, no destinada en principio a la costosa puesta en escena cortesana, sino a la más austera del corral.

Tanto la actividad de los corrales como las estrategias editoriales, al publicar su teatro con las dedicatorias a Olivares y a otros nobles y mecenas, son complementarias de la incansable búsqueda de mecenazgo cortesano que lleva a cabo el último Lope: «a la sombra de palacio, si bien falto de protección» (Carreño 2020:260). Los mismos criterios de selección de las comedias incluidas en las dos últimas Partes XXI-XXII muestran su interés por la autopromoción de una imagen alejada de la irreverencia más característica del primer Lope, como ocurre también en las piezas incluidas en La vega del Parnaso, tan condicionadas por el mecenazgo regio y nobiliario (Florit Durán 2019). Son obras en general las del último Lope, como afirma Antonio Sánchez Jiménez [2018:305], al hacer su balance: «imbuidas, como el resto de su producción de esta etapa, por la estética e intereses cortesanos».

Como muestra de la variedad de cauces que adquiere la cortesanización, se pueden recordar otros rasgos del último periodo de su teatro, como la predilección por las piezas de tema mitológico, menos frecuente en sus primeras etapas; la ambientación palatina predominante, como ocurre en La vega del Parnaso, en sus comedias amatorias últimas (Oleza 2003), donde se produce el «indefectible retorno a la corte. Aunque los personajes confiesan que la aldea es el lugar de la felicidad, ninguno de ellos termina la comedia viviendo en el campo» (Rivera Salmerón 2019:443); las sucesivas representaciones cortesanas, desde El vellocino de oro al Diálogo militar y a $E l$ Amor enamorado; o su predilección por el estilo trágico de $E l$ castigo sin venganza donde, entre otros motivos como el sugerido por el subtítulo... cuando Lope quiere, se apunta a la capacidad del comediógrafo para componer una obra de prestigio, de acuerdo con la tendencia del género en los años veinte y treinta (d'Artois 2017) hacia una reformulación más aristotélica.

33. Si bien destaca Garrot Zambrana [2021:384] «la presencia de la ciudad, Madrid, de su espacio urbano con lugares representativos», desde el inicio de Las bizarrías de Belisa cuando la protagonista epónima narra su enamoramiento fulminante de don Juan de Cardona, cuyo apellido es un homenaje al último y más influyente de sus mecenas, el duque de Sessa (Luis Fernández de Córdoba, Cardona y Aragón), ocurrido en el Paseo del Prado precisamente, se dibuja con nitidez el imaginario cortesano sobre la geografía madrileña donde se desarrolla el conflicto amoroso dependiente de los valores nobiliarios y del ennoblecimiento de su dramatis personae. 
La voluntad clasicista que manifiesta Lope de Vega al elevar el patrón trágico, o al recurrir a la tradición mitológica, tampoco excluye, sino todo lo contrario, la diversidad de estrategias editoriales empleadas en las Partes bajo su control, ni la progresiva cortesanización de su teatro. Lo hemos comprobado mediante el análisis del Diálogo militar, cuya escritura viene condicionada por la búsqueda del mecenazgo cortesano, dentro de la misma serie de publicaciones que transcurre desde las Partes XXI-XXII a La vega del Parnaso. 


\section{BIBLIOGRAFÍA}

Álvarez Junco, José, Mater Dolorosa. La idea de España en el siglo XIX, Taurus, Madrid, 2001.

Arata, Stefano [2000]: véase Vega CARPIo, Lope de, El acero de Madrid.

Barrera, Cayetano Alberto de la, Nueva biografía de Lope de Vega [1880-1890]; reimp. Atlas, Madrid, 1973-1974, 2 vols.

BouRdieu, Pierre, Las reglas del arte. Génesis y estructura del campo literario [1992], trad. Th. Kauf, Anagrama, Barcelona, 1995.

BouzA, Fernando, «Política del libro del Consejo Real en el tiempo de Olivares», en Poder y saber. Bibliotecas y bibliofilia en la época del conde-duque de Olivares, eds. O. Noble Wood, J. Roe y J. Lawrance, Centro de Estudios Europa Hispánica, Madrid, 2011, pp. 339-362.

BRIOSO SANTOS, Héctor, «"Con pobreza pretendî”: la caballería tronada y la figura del pretendiente en la corte según Cervantes, Guillén de Castro y Cristóbal Suárez de Figueroa», Libros de la Corte.es, XXI (2020), pp. 176-202.

CARREÑo, Antonio, Que en tantos cuerpos vive repetido (Las voces líricas de Lope de Vega), Cátedra, Madrid, 2020.

Colomer, José Luis, «Ambrosio Spinola. Fortuna iconográfica de un genovés al servicio de la Monarquía», en España y Génova. Obras, artistas y coleccionistas, dirs. J. L. Colomer y C. Di Fabio, CEEH-Fundación Carolina, Madrid, 2002, pp. 157-175.

CoRtiJo OcaÑa, Antonio, La porfía: Identidad personal y nacional en Lope de Vega, Anthropos, Barcelona, 2013.

Crivellari, Daniele, «Textos y diálogos en diálogo: Barlaán y Josafat de Lope de Vega», en La edición del diálogo teatral (siglos XVI-XVII), eds. L. Giuliani y V. Pineda, Firenze University Press, Florencia, 2021a, pp. 41-62.

CRivellari, Daniele [2021b]: véase Vega CarPio, Lope de, Barlaán y Josafat.

Cuenca Muñoz, Paloma, «Estudio diplomático de los testamentos de Lope de Vega», Bulletin Hispanique, CXXIII (2021), pp. 335-350.

D’ARтоIS, Florence, «Hacia un patrón de lectura genérico de las partes de comedias: tragedias y tragicomedias en las Partes XVI y XX de Lope de Vega», en «Aún no dejó la pluma». Estudios sobre el teatro de Lope de Vega, ed. X. Tubau, PROLOPE-Universitat Autònoma de Barcelona, Bellaterra, 2009, pp. 285-322. 
D’Artois, Florence, Lope de Vega, la «tragedia» et son public, Casa de Velázquez, Madrid, 2017.

De la Flor, Fernando R., El sol de Flandes. Imaginarios bélicos del Siglo de Oro, Delirio, Salamanca, 2018.

Dixon, Victor, «La intervención de Lope en la publicación de sus comedias», Anuario Lope de Vega, II (1996), pp. 45-63.

FerRer, Teresa, «El vellocino de oro y El Amor enamorado», en En torno al teatro del Siglo de Oro. Actas de las Jornadas XII-XIII celebradas en Almería, ed. J.J. Berbel, Instituto de Estudios Almerienses-Diputación de Almería, Almería, 1996, pp. 49-63.

FERRER, Teresa, «Lope representado en palacio en la época de Felipe IV: hipótesis a partir de la base de datos CATCOM», Teatro de palabras, VII (2013), pp. 173-192.

FERRer, Teresa, «El Diálogo militar a honor del marqués de Espínola: Lope de Vega y el afán de proyección social», en Diferentes y escogidas. Homenaje al prof. Luis Iglesias Feijoo, ed. S. Fernández Mosquera, Iberoamericana-Vervuert, Madrid-Frankfurt am Main, 2014, pp. 163-182.

Florit Durán, Francisco, «"Vuestra oliva es laurel de mi cabeza”: Lope de Vega y la búsqueda del Parnaso áulico», Anuario de Estudios Filológicos, XLII (2019), pp. 63-85.

GARCíA-REIDY, Alejandro, Las musas rameras. Oficio dramático y conciencia profesional en Lope de Vega, TC/12-Iberoamericana-Vervuert, Madrid-Frankfurt am Main, 2013.

García-Reidy, Alejandro, y Fernando Plata [2020]: véase Vega Carpio, Lope de, Comedias de Lope de Vega. Parte XIX.

García-Reidy, Alejandro, Ramón Valdés y Germán Vega García-Luengos, «Una nueva edición (iprinceps?) de El castigo sin venganza», Anuario Lope de Vega. Texto, literatura, cultura, XXVII (2021), pp. 270-329.

Garrot Zambrana, Juan Carlos, «Lope se despide de los corrales: Las bizarrías de Be-

lisa», Anuario Lope de Vega. Texto, literatura, cultura, XXVI (2020), pp. 379-403.

Gómez, Jesús, Individuo y sociedad en las comedias (1580-1604) de Lope de Vega, Universidad Autónoma de Madrid, Madrid, 2000.

Gómez, Jesús, El modelo teatral del último Lope de Vega (1621-1635), Universidad de Valladolid-Ayuntamiento de Olmedo, Valladolid, 2013. 
Gómez, Jesús, La literatura y el ocio en la sociedad cortesana del Siglo de Oro, Universidad de Salamanca, Salamanca, 2021.

Ioppoli, Eleonora, «Estudio» a Lope de Vega Carpio, La mayor victoria de Alemania de don Gonzalo de Córdoba, en La vega del Parnaso, dirs. F.B. Pedraza Jiménez y P. Conde Parrado, Ediciones de la Universidad de Castilla-La Mancha, Cuenca, 2015, vol. 3, pp. 385-404.

Martínez Berbel, José Antonio, El mundo mitológico de Lope de Vega. Siete comedias mitológicas de inspiración ovidiana, FUE, Madrid, 2003.

Menéndez Pelayo, Marcelino, Estudios sobre el teatro de Lope de Vega, ed. E. Sánchez Reyes, Aldus, Santander, 1949, 6 vols.

Moll, Jaime, «Diez años sin licencias para imprimir comedias y novelas en los reinos de Castilla: 1625-1634», Boletín de la Real Academia Española, LIV (1974), pp. 97-103.

Moll, Jaime, «Por qué escribió Lope La Dorotea (Contribución de la historia del libro a la historia literaria)», 1616, II (1979), pp. 7-11.

Moll, Jaime, «Los editores de Lope de Vega», Edad de Oro, XIV (1995), pp. 213-222.

Moll, Jaime, «De la continuación de las partes de comedias de Lope de Vega a las partes colectivas», en Homenaje a Alonso Zamora Vicente, Castalia, Madrid, 1992, vol. III 2, pp. 199-211.

Morley, S. Griswold, y Courtney Bruerton, Cronología de las comedias de Lope de Vega, trad. M. R. Cartes, Madrid, Gredos, 1968.

OlEzA, Joan, «Hipótesis sobre la génesis de la comedia barroca y la historia teatral del siglo XVI» (1981), en Teatro y prácticas escénicas, I. El Quinientos valenciano, dir. J. Oleza, Institució Alfons el Magnànim, Valencia, 1984, pp. 9-42.

OlezA, Joan, «Del primer Lope al "Arte nuevo"», en Peribáñez y el comendador de Ocaña, ed. D. McGrady, Crítica, Barcelona, 1997, pp. ix-lv.

OlEZA, Joan, «El Lope de los últimos años y la materia palatina», Criticón, LXXXVIILXXXVIII-LXXXIX (2003), pp. 603-620.

OlezA, Joan, «Historical Dramas of Private Events, by Lope de Vega: a Requirement of Subjects», From Ancient Classical to Modern Classical: Lope de Vega and the New Challenges of Spanish Theatre, IDEA-IGAS, Nueva York, 2012, pp. 61-102.

Pedraza, Felipe B., "La vega del Parnaso de Lope: la estructura que quiso ser y no fue», Criticón, CXXII (2014), pp. 27-40. 
Pedraza, Felipe B. [2015]: véase Vega Carpio, Lope de, La vega del Parnaso.

Pérez Reverte, Arturo, El sol de Breda, Alfaguara, Madrid, 2002.

Profeti, Maria Grazia, La collezione «Diferentes autores», Reichenberger, Kassel, 1988.

Profeti, Maria Grazia, «El último Lope», en La década de oro de la comedia española, 1630-1640. Actas de las XIX Jornadas de teatro clásico. Almagro, 9-11 de julio, eds. F.B. Pedraza y R. González Cañal, Universidad de Castilla-La ManchaFestival de Almagro, Almagro (Ciudad Real), 1997, pp. 11-39.

Profeti, Maria Grazia, «Strategie redazionali ed editoriali di Lope de Vega», Nell'officina di Lope, Alinea, Florencia, 1998, pp. 11-44.

Rennert, Hugo A., y Américo Castro, Vida de Lope de Vega, Anaya, Salamanca, 1968.

Rivera SAlmerón, Esperanza, «Vaivenes de un tópico: la contraposición corte y aldea en el último Lope de Vega», Revista de Literatura, LXXXI (2019), pp. 423-449. Rivero, Manuel, El conde duque de Olivares. La búsqueda de la privanza perfecta, Polifemo, Madrid, 2017.

Rodríguez, José Javier [2020]: véase VEGA CARPIO, Lope de, El vellocino de oro. Rodríguez-Gallego, Fernando [2015]: véase Vega CARPio, Lope de, Diálogo militar. Rodríguez-Gallego, Fernando, «Sobre la fuente, las circunstancias de creación y la fecha del Diálogo militar a honor de Espínola de Lope de Vega», Anuario Lope de Vega. Texto, literatura, cultura, XXII (2016), pp. 387-408.

Rodríguez-Gallego, Fernando, «El texto de la segunda parte de Don Juan de Castro: entre las Partes XIX y XXV», Anuario Lope de Vega. Texto, literatura, cultura, XXVI (2020), pp. 548-575.

Rodríguez PÉrez, Yolanda, The Dutch Revolt through Spanish Eyes, Peter Lang, Berna, 2008.

Rodríguez Pérez, Yolanda, Antonio Sánchez Jiménez, y Harn Den Boer, eds., España antes sus críticos. Las claves de la Leyenda Negra, Iberoamericana-Vervuert, Madrid-Frankfurt am Main, 2015.

Rodríguez Pérez, Yolanda, y Antonio SÁnchez Jiménez, eds., La Leyenda Negra en el crisol de la comedia. El teatro del Siglo de Oro frente a los estereotipos antihispánicos, Iberoamericana-Vervuert, Madrid-Frankfurt am Main, 2016.

RozAs, Juan Manuel, Estudios sobre Lope de Vega, ed. J. Cañas Murillo, Cátedra, Madrid, 1990.

SÁEz Raposo, Francisco, Todo Madrid es teatro. Los escenarios de la Villa y Corte en 
el Siglo de Oro, Comunidad Autónoma de Madrid-Casa de Lope de Vega, Madrid, 2018.

Sánchez Aguilar, Agustín, Lejos del Olimpo. El teatro mitológico de Lope de Vega, Universidad de Extremadura, Cáceres, 2010.

SÁnchez Jiménez, Antonio, Leyenda Negra. La batalla sobre la imagen de España en tiempos de Lope de Vega, Cátedra, Madrid, 2016.

SÁnchez Jiménez, Antonio, Lope: el verso y la vida, Cátedra, Madrid, 2018.

SANZ AyÁn, Carmen, «Reproches de ida y vuelta. Opiniones recíprocas hispano-genovesas en el Siglo de Oro», en España ante sus críticos. Las claves de la Leyenda Negra, Iberoamericana-Vervuert, Madrid-Frankfurt am Main, 2015, pp. 231-253.

Schreckenberg, Stefan, «El sitio de Breda de Calderón y Las lanzas de Velázquez en El sol de Breda de Arturo Pérez Reverte. Transformaciones de un lugar de memoria», en El Siglo de Oro en la España contemporánea, eds. H. Ehrlischer y S. Schreckenberg, Iberomaricana-Vervuert, Madrid-Frankfurt am Main, 2011, pp. 213-232.

Trambaiol, Marcela, «La fama póstuma de Lope de Vega», Studia Aurea, X (2016), pp. 175-199.

UsANDIZAGa, Guillem, La representación de la historia contemporánea en el teatro de Lope de Vega, TC/12-Iberoamericana-Vervuert, Madrid-Franfurt am Main, 2014. UsunáRIZ, Jesús M., «¿Paz entre cristianos o guerra contra los herejes? La crítica hispana ante la política exterior de la Monarquía Hispánica (siglos XVI-XVII)», en La autoridad política y el poder de las letras en el Siglo de Oro, eds. J.M. Usunáriz y E. Williamson, Iberoamricana-Vervuert, Madrid-Franfurt am Main, 2013, pp. 201-224.

VArey, John E., y N.D. Shergold, Fuentes para la historia del teatro en España, IX. Comedias en Madrid, 1603-1709. Repertorio y estudio bibliográfico, Tamesis Books, Londres, 1989.

Vega Carpio, Lope de, El acero de Madrid, ed. S. Arata, Castalia, Madrid, 2000.

Vega Carpio, Lope de, Barlaán y Josafat, ed. D. Crivellari, Cátedra, Madrid, 2021.

Vega CARPIo, Lope de, Las bizarrías de Belisa, ed. E. García Santo-Tomás, Cátedra, Madrid, 2004.

VEGA CARPIO, Lope de, La boba para los otros y discreta para sí, ed. A. Zapatero Molinuevo, Cátedra, Madrid, 2020. 
Vega Carpio, Lope de, Cartas (1604-1633), ed. A. Carreño, Cátedra, Madrid, 2018.

Vega Carpio, Lope de, Comedias de Lope de Vega. Parte XIX, coords. A. García-Reidy y F. Plata, Madrid, Gredos, 2020, 2 vols.

VEGa CARPIo, Lope de, Diálogo militar a honor del excelentísimo marqués de Espínola, ed. F. Rodríguez-Gallego, en La vega del Parnaso, dirs. F.B. Pedraza Jiménez y P. Conde Parrado, Ediciones de la Universidad de Castilla-La Mancha, Cuenca, 2015, vol. 3, pp. 283-347.

Vega Carpio, Lope de, La Dorotea, ed. J.M. Blecua, Cátedra, Madrid, 1996.

VEGa CARPIo, Lope de, La mayor victoria de Alemania de don Gonzalo de Córdoba, ed. E. Ioppoli, en La vega del Parnaso, dirs. F.B. Pedraza Jiménez y P. Conde Parrado, Ediciones de la Universidad de Castilla-La Mancha, Cuenca, 2015, vol. 3, pp. 385-551.

Vega Carpio, Lope de, La vega del Parnaso, dirs. F.B. Pedraza Jiménez y P. Conde Parrado, Ediciones de la Universidad de Castilla-La Mancha, Cuenca, 2015, 3 vols.

VEga CARPIo, Lope de, El vellocino de oro, ed. J.J. Rodríguez, en Comedias de Lope de Vega. Parte XIX, coords. A. García-Reidy y F. Plata, Gredos, Madrid, 2020, vol. 2, pp. 515-570.

Vosters, Simon A., La rendición de Breda en la literatura y el arte de España, Tamesis, Londres, 1974.

Zapatero Molinuevo, Ane [2020]: véase Vega Carpio, Lope de, La boba para los otros. 